\title{
Desenvolvimento de preparações vegetarianas à base de leguminosas para o público
}

\section{pré-escolar}

\author{
Development of vegetarian preparations based on legumes for the pre-school public \\ Desarrollo de preparaciones vegetarianas basados en legumbres para el público pré-escolar
}

\section{Resumo}

O presente estudo tem por objetivo desenvolver preparações vegetarianas para pré-escolares e caracterizá-las quanto à composição nutricional e ao custo. Realizou-se busca, seleção e teste de 23 preparações vegetarianas, com padronização de fichas técnicas de preparo, cálculo do valor nutricional e custo da porção. Utilizaram-se tabelas de composição de alimentos e os guias alimentares. As porções das preparações vegetarianas foram comparadas entre si quanto a sua composição nutricional, e com as preparações de origem animal, ofertadas em um Centro de Educação Infantil, bem como aos valores de referência do Programa Nacional de Alimentação Escolar. Das 23 preparações desenvolvidas, nove eram à base de grão de bico; oito de feijão, ervilha e lentilha e seis de soja e proteína texturizada de soja. As que se destacaram quanto à composição nutricional geral foram: almôndegas de feijão branco, hambúrguer de feijão, almôndegas de soja, mini almôndegas e estrogonofe de proteína texturizada de soja, com custo variando de $\mathrm{R}$ \$ 0,18 a R \$ 0,64. As preparações vegetarianas desenvolvidas contribuíram satisfatoriamente com as recomendações do Programa Nacional de Alimentação Escolar e apresentaram, em sua maioria, composição nutricional superior aos pratos de origem animal avaliados. Assim, é possível inferir que as preparações à base de leguminosas são aptas a integrar o cardápio de escolares.

Palavras-chave: Vegetarianismo; Criança; Receitas dietéticas; Leguminosas; Alimentação escolar.

\begin{abstract}
The present study aims to develop vegetarian preparations for preschoolers and characterize them in terms of nutritional composition and cost. A search, selection and test of 23 vegetarian preparations was carried out, with standardization of technical preparation sheets, calculation of the nutritional value and cost of the portion. Food composition tables and food guides were used. The portions of the vegetarian preparations were compared among themselves as to their nutritional composition, and with the preparations of animal origin, offered at a Child Education Center, as well as the reference values of the National School Feeding Program. Of the 23 preparations developed, nine were based on chickpeas; eight of beans, peas and lentils and six of soy and textured soy protein. White bean meatballs, bean burger, soy meatballs, mini meatballs and textured soy protein stroganoff, stood out in terms of nutritional composition, with cost ranging from $\mathrm{R} \$ 0.18$ to $\mathrm{R} \$ 0.64$. The vegetarian preparations developed contributed satisfactorily to the recommendations of the National School Feeding Program and presented, for the most part, a composition superior to the evaluated animal dishes. Thus, it is possible to infer that legume-based preparations are suitable to be part of the school menu.
\end{abstract}

Keywords: Vegetarianism; Child; Diet recipes; Legumes; School feeding. 


\begin{abstract}
Resumen
El presente estudio tiene como objetivo desarrollar preparaciones vegetarianas para niños en edad preescolar y caracterizarlas en términos de composición nutricional. Se realizó una búsqueda, selección y muestreo de 23 preparaciones vegetarianas, con estandarización de fichas técnicas de preparación, cálculo del valor nutricional y costo de la porción. Se utilizaron tablas de composición de alimentos y guías de alimentos. Las porciones de las preparaciones vegetarianas se compararon entre sí en cuanto a su composición nutricional, y se compararon con preparaciones de origen animal, ofrecidas en un Centro de Educación Infantil, así como los valores de referencia del Programa Nacional de Alimentación Escolar. De las 23 preparaciones desarrolladas, nueve se basaron en garbanzos; ocho en frijoles, guisantes y lentejas, y seis de soja y proteína de soja texturizada. Los que se destacaron en cuanto a composición nutricional fueron: albóndigas de frijoles blancos, hamburguesa de frijoles, albóndigas de soja, mini albóndigas y stroganoff proteína de soja texturizada, con un costo que oscila entre $\mathrm{R} \$ 0,18$ a $\mathrm{R} \$ 0,64$. Las preparaciones vegetarianas desarrolladas contribuyeron satisfactoriamente a las recomendaciones del Programa Nacional de Alimentación Escolar y presentaron, en su mayor parte, una composición superior a los platos animales evaluados. Así, es posible inferir que las preparaciones a base de leguminosas son adecuadas para formar parte del menú escolar.
\end{abstract}

Palabras clave: Vegetarianismo; Niño; Recetas de dieta; Leguminosas; Alimentación escolar.

\title{
1. Introdução
}

O vegetarianismo consiste na exclusão de todos os tipos de carne da alimentação e, segundo a frequência de ingestão de alimentos de origem animal, pode ser classificado como ovolactovegetarianismo, lactovegetarianismo, ovovegetarianismo, vegetarianismo estrito e veganismo (Couceiro, Slywitch \& Lenz, 2008). A adesão a essa prática apresenta motivações diversas como ética, ambiental, cultural, religiosa e de saúde (Azevedo, 2013) que podem estar relacionadas às tendências da alimentação como saudabilidade, sustentabilidade e ética (Barbosa, Madi, Toledo \& Rego, 2010).

Trata-se de uma prática alimentar em ascensão (Leitzmann, 2014) que foi relatada por $14 \%$ dos brasileiros em uma consulta pública realizada em 2018 (Instituto Brasileiro de Opinião Pública e Estatística, 2018). Além disso, é reconhecida por ser apropriada em todas as fases da vida incluindo a gravidez, lactação e infância e, quando bem planejada, é nutricionalmente adequada e saudável, fornecendo benefícios à saúde (Melina, Craig \& Levin, 2016) e auxiliando na prevenção e no tratamento de doenças (Teixeira, Molina, Flor, Zandonade \& Mill 2006; Melina et al., 2016).

Quanto ao período da infância, é notório o intenso desenvolvimento nas esferas físicas, mentais, emocionais e afetivas da criança, inclusive os aspectos relacionados à capacidade de aprendizado (Cabral et al., 2020). Sabe-se que as experiências vivenciadas nesta fase, marcada por curiosidade aguçada e busca por novidades, tornam o momento propício para intervenções em saúde que poderão resultar em comportamentos adequados que tendem a se manter na vida adulta e impactar em seu desenvolvimento futuro (O’Connor, 2011; Brasil, 2019).

A nutrição adequada desde o nascimento é fundamental para o alcance do potencial de crescimento e desenvolvimento infantis e na consolidação de hábitos saudáveis (De Cosmi, Scaglioni \& Agostoni, 2017). Tal fato aliado à prevalência crescente do vegetarianismo, contribuiu para que a opção da alimentação vegetariana fosse implementada no ambiente escolar pelo Programa Nacional de Alimentação Escolar (PNAE) por meio da nota técnica $n^{\circ} 8$ de 2019 que preconiza o fornecimento e adequação desta opção (Brasil, 2019). Neste sentido, faz-se necessário o desenvolvimento de preparações mais saudáveis e sustentáveis para inserção nos cardápios escolares, reconhecendo-os como instrumentos de educação alimentar e nutricional (Lobato, Silva, Cramês, Santos \& Graça, 2016; Monteiro, De Paula, Da Silva, Moretti \& Maniglia, 2019; Brasil, 2020).

Diante do exposto, o presente estudo tem como objetivo desenvolver preparações vegetarianas para pré-escolares e caracterizá-las quanto à composição nutricional e ao custo.

\section{Metodologia}

Trata-se de um estudo experimental que compreendeu o desenvolvimento de preparações vegetarianas com potencial 
de inserção em cardápios escolares. Inicialmente procedeu-se à busca e seleção de receituários na base de dados do Google por meio da palavra-chave "receitas vegetarianas". Baseados nesses resultados, selecionaram-se 23 preparações que seguiram para testagem e adaptações no Laboratório de Técnica Dietética da Universidade Federal do Espírito Santo - UFES. Nesta etapa, todos os ingredientes foram pesados, antes e após o pré-preparo e a cocção, com auxílio da balança digital marca/modelo Even-CT-6200AS-BI®, capacidade máxima de $6200 \mathrm{~g}$ e precisão de $0,01 \mathrm{~g}$. Além disso, foram utilizados equipamentos de armazenamento (refrigeradores domésticos) e de cocção (fogão doméstico e forno).

Após a padronização dos receituários, elaboraram-se as fichas técnicas de preparo dos pratos vegetarianos desenvolvidos e o porcionamento foi baseado no Guia Alimentar Infantil (Brasil, 2005). Foi realizado cálculo da composição nutricional preconizada pelo PNAE (Brasil, 2020) com auxílio de duas tabelas brasileiras de composição de alimentos (Philippi, 2002; UNICAMP, 2011) e rótulos de alimentos. O cálculo do custo por porção foi estimado baseando-se nos valores de gêneros encontrados nas redes de mercado local.

A composição nutricional das 23 preparações desenvolvidas foi comparada com valores de referência para refeição estabelecidos pelo PNAE na faixa etária de quatro a cinco anos, correspondente ao atendimento de $20 \%$ das necessidades diárias, a saber: 270,0 kcal de valor energético; 8,4 g de proteína; 43,9 g de carboidratos; 6,8 g de lipídeos; 5,0 g de fibras; 80,0 mcg de vitamina A; 5,0 mg de vitamina C; 160,0 mg de cálcio; 1,0 mg de zinco; $26 \mathrm{mg}$ de magnésio e 2,0 mg de ferro (Brasil, 2020). Além disso, as preparações desenvolvidas foram comparadas entre si e com três pratos à base de produtos de origem animal (Carne Moída, Frango Desfiado e Ovo Cozido) ofertados em um Centro de Educação Infantil (CEI) vinculado a uma instituição pública de ensino localizado em Vitória - ES.

Os dados foram armazenados no Microsoft Excel® e analisados na forma de estatística descritiva (média, desviopadrão, frequência). Calculou-se o percentual de contribuição no valor nutricional da refeição recomendado pelo PNAE para as preparações desenvolvidas e ofertadas no CEI de referência.

\section{Resultados}

Após o levantamento das receitas vegetarianas viáveis para o público infantil foram selecionadas, testadas e padronizadas 23 preparações utilizando como base as leguminosas: grão de bico (n=9), feijão, lentilha e ervilha ( $n=8$ ), soja e proteína texturizada de soja - PTS $(n=6)$. Informações nutricionais por porção das preparações, segundo leguminosas, estão apresentadas nas tabelas 1,2 e 3 .

No que diz respeito às preparações à base de grão de bico (Tabela 1), a média do peso de porção verificada foi 38,56 $\pm 14,25 \mathrm{~g}$ e do valor energético correspondeu à de $61,11 \pm 7,34 \mathrm{kcal}$. Quanto à contribuição dos macronutrientes no valor energético, verificou-se, em média, $18,26 \%$ para proteínas, $58,12 \%$ e $27,82 \%$, para carboidratos e lipídios, respectivamente. A composição nutricional dessas preparações apresentou variação, conforme Tabela 1. 
Tabela 1. Composição nutricional por porção das preparações vegetarianas à base de grão de bico propostas para o público infantil. Vitória - ES, 2019/2020.

\begin{tabular}{|c|c|c|c|c|c|c|c|c|c|c|c|c|}
\hline Preparação & Porção (g) & $\begin{array}{c}\text { Valor } \\
\text { energético } \\
\text { (kcal) }\end{array}$ & PTN (g) & $\begin{array}{c}\text { CHO } \\
(\mathrm{g})\end{array}$ & $\underset{(g)}{\text { LIP }}$ & $\begin{array}{l}\text { Fibras } \\
\text { (g) }\end{array}$ & $\begin{array}{l}\text { Vit.A } \\
\text { (mcg) }\end{array}$ & $\begin{array}{l}\text { Vit.C } \\
\text { (mg) }\end{array}$ & $\underset{(\mathbf{m g})}{\mathrm{Ca}}$ & $\begin{array}{l}\mathrm{Zn} \\
(\mathbf{m g})\end{array}$ & $\begin{array}{c}\text { Mg } \\
(\mathbf{m g})\end{array}$ & $\underset{(\mathbf{m g})}{\mathrm{Fe}}$ \\
\hline $\begin{array}{l}\text { Almôndega de } \\
\text { Grão de Bico }\end{array}$ & 32,39 & 58,04 & 2,72 & 9,26 & 1,33 & 1,93 & 282,69 & 1,42 & 17,50 & 0,41 & 18,50 & 0,76 \\
\hline $\begin{array}{l}\text { Cozido } \\
\text { Simples de } \\
\text { Grão de Bico }\end{array}$ & 40,20 & 53,40 & 2,63 & 7,60 & 1,62 & 1,72 & 12,13 & 2,95 & 15,84 & 0,38 & 18,37 & 0,64 \\
\hline $\begin{array}{l}\text { Estrogonofe } \\
\text { de Grão de } \\
\text { Bico }\end{array}$ & 60,20 & 66,02 & 3,48 & 8,08 & 2,64 & 1,34 & 17,92 & 3,64 & 48,20 & 0,40 & 16,89 & 0,50 \\
\hline $\begin{array}{l}\text { Moqueca de } \\
\text { Grão de Bico } \\
\text { e Banana da } \\
\text { Terra }\end{array}$ & 61,00 & 62,79 & 2,30 & 12,20 & 1,06 & 1,70 & 21,18 & 8,82 & 12,99 & 0,33 & 19,44 & 0,55 \\
\hline $\begin{array}{l}\text { Nuggets de } \\
\text { Grão de Bico } \\
\text { e Legumes }\end{array}$ & 25,80 & 72,04 & 2,45 & 10,08 & 2,57 & 2,18 & 123,40 & 2,39 & 15,19 & 0,53 & 15,82 & 0,71 \\
\hline $\begin{array}{l}\text { Omelete de } \\
\text { Grão de Bico }\end{array}$ & 36,90 & 56,40 & 3,19 & 9,08 & 1,05 & 2,01 & 7,95 & 1,84 & 18,54 & 0,47 & 22,07 & 0,80 \\
\hline $\begin{array}{l}\text { Petisco de } \\
\text { Grão de Bico }\end{array}$ & 18,35 & 71,34 & 2,91 & 8,07 & 3,27 & 1,76 & 0,46 & 0,17 & 17,07 & 0,45 & 20,61 & 0,80 \\
\hline $\begin{array}{l}\text { Quibe Assado } \\
\text { de Grão de } \\
\text { Bico }\end{array}$ & 32,50 & 52,30 & 2,19 & 8,49 & 1,34 & 1,44 & 3,17 & 1,04 & 12,45 & 0,33 & 18,95 & 0,55 \\
\hline $\begin{array}{l}\text { Torta de PTS } \\
\text { com massa de } \\
\text { Grão de Bico }\end{array}$ & 39,66 & 57,69 & 3,24 & 7,06 & 2,12 & 1,82 & 193,73 & 5,42 & 14,33 & 0,26 & 13,90 & 0,47 \\
\hline Média $\pm D P$ & $38,56 \pm 14,25$ & $61,11 \pm 7,34$ & $2,79 \pm 0,45$ & $\begin{array}{c}8,88 \pm \\
1,54\end{array}$ & $\begin{array}{c}1,89 \pm \\
0,80\end{array}$ & $\begin{array}{c}1,77 \pm \\
0,26\end{array}$ & $\begin{array}{l}73,63 \pm \\
103,00\end{array}$ & $\begin{array}{c}3,08 \pm \\
2,65\end{array}$ & $\begin{array}{c}19,12 \pm \\
11,09\end{array}$ & $\begin{array}{c}0,40 \pm \\
0,08\end{array}$ & $\begin{array}{c}18,28 \pm \\
2,47\end{array}$ & $\begin{array}{c}0,64 \pm \\
0,13\end{array}$ \\
\hline $\begin{array}{l}\text { Coeficiente de } \\
\text { Variação (\%) }\end{array}$ & 36,96 & 12,01 & 16,04 & 17,37 & 42,11 & 14,89 & 139,90 & 86,11 & 57,99 & 20,77 & 13,51 & 20,21 \\
\hline
\end{tabular}

Legenda: PTN: Proteína; CHO: Carboidratos. LIP: Lipídeos; Vit. A: Vitamina A; Vit. C: Vitamina C; Ca: Cálcio; Zn: Zinco; Mg: Magnésio; Fe: Ferro.

Fonte: Autores.

Ao comparar as preparações à base de grão de bico com as recomendações nutricionais por refeição do PNAE, observa-se variação no conteúdo de macronutrientes sendo os percentuais respectivos: 16,08 a 27,79 para os carboidratos; 26,07 a 38,57 para proteínas e 15,44 a 48,04 para os lipídios. Quanto aos micronutrientes e fibras desse grupo, observou-se percentual respectivo para: vitamina A $(0,57$ a 353,36), vitamina C (3,36 a 176,40), magnésio $(53,46$ a 84,88), ferro $(23,50$ a 40,00), zinco (26,00 a 53,00), cálcio (7,78 a 30,13) e fibras $(26,80$ a 43,55).

$\mathrm{O}$ custo por porção médio dessas preparações foi $\mathrm{R} \$ 0,28 \pm 0,08$, variando de $\mathrm{R} \$ 0,22$ (almôndegas, petiscos e quibe assado de grão de bico) a R 0,45 (moqueca de grão de bico com banana da terra).

Na Tabela 2 estão apresentadas as informações nutricionais por porção das preparações à base de feijão, ervilha e lentilha. Nota-se que o peso das porções médio foi de $38,14 \pm 12,12 \mathrm{~g}$ e o valor energético médio correspondeu a $66,96 \pm 2,34$ 
kcal. O percentual médio de contribuição energética das proteínas correspondeu a $24,24 \%$, enquanto para os carboidratos, $67,27 \%$, e $15,32 \%$ nos lipídios.

Entre as oito preparações à base dessas leguminosas destaca-se as almôndegas de feijão branco e o hambúrguer de feijão como sendo as que apresentaram melhor composição nutricional, variando entre essas duas preparações os maiores valores energéticos, proteínas, carboidratos, fibras, cálcio, zinco, magnésio e ferro (Tabela 2).

Tabela 2. Composição nutricional por porção das preparações vegetarianas à base de feijão, ervilha e lentilha propostas para público infantil. Vitória - ES, 2019/2020.

\begin{tabular}{|c|c|c|c|c|c|c|c|c|c|c|c|c|}
\hline Preparação & Porção (g) & $\begin{array}{c}\text { Valor } \\
\text { energético } \\
\text { (kcal) }\end{array}$ & $\begin{array}{c}\text { PTN } \\
(g)\end{array}$ & $\underset{(\mathrm{g})}{\mathrm{CHO}}$ & $\begin{array}{l}\text { LIP } \\
(\mathrm{g})\end{array}$ & $\begin{array}{c}\text { Fibras } \\
\text { (g) }\end{array}$ & $\begin{array}{l}\text { Vit.A } \\
\text { (mcg) }\end{array}$ & $\begin{array}{l}\text { Vit.C } \\
\text { (mg) }\end{array}$ & $\begin{array}{c}\mathrm{Ca} \\
(\mathbf{m g})\end{array}$ & $\begin{array}{l}\mathbf{Z n} \\
(\mathbf{m g})\end{array}$ & $\begin{array}{l}\mathrm{Mg} \\
(\mathbf{m g})\end{array}$ & $\begin{array}{c}\mathbf{F e} \\
(\mathbf{m g})\end{array}$ \\
\hline $\begin{array}{l}\text { Almôndegas de } \\
\text { Feijão Branco }\end{array}$ & 46,80 & 66,74 & 4,20 & 11,77 & 0,68 & 3,67 & 7,58 & 1,81 & 47,71 & 0,56 & 34,27 & 1,90 \\
\hline $\begin{array}{l}\text { Almôndegas de } \\
\text { Lentilha }\end{array}$ & 31,07 & 65,61 & 3,74 & 11,61 & 0,67 & 2,75 & 9,27 & 1,13 & 13,03 & 0,59 & 18,79 & 1,17 \\
\hline $\begin{array}{lr}\text { Bolinho } & \text { de } \\
\text { Feijão } & \text { com } \\
\text { Abóbora } & \end{array}$ & 34,00 & 64,68 & 3,22 & 10,96 & 1,10 & 2,93 & 22,82 & 0,84 & 19,70 & 0,48 & 31,82 & 1,20 \\
\hline $\begin{array}{l}\text { Hambúrguer } \\
\text { de Ervilha }\end{array}$ & 25,50 & 67,98 & 4,50 & 11,42 & 1,18 & 0,98 & 13,20 & 1,88 & 29,40 & 0,08 & 3,43 & 0,86 \\
\hline $\begin{array}{l}\text { Hambúrguer } \\
\text { de Feijão }\end{array}$ & 35,50 & 70,52 & 4,52 & 12,18 & 1,13 & 3,03 & 8,99 & 1,77 & 34,11 & 0,44 & 26,53 & 0,95 \\
\hline $\begin{array}{l}\text { Hambúrguer } \\
\text { de Lentilha }\end{array}$ & 27,00 & 65,25 & 4,32 & 11,18 & 1,00 & 2,20 & 6,84 & 0,80 & 22,28 & 0,46 & 14,33 & 0,87 \\
\hline $\begin{array}{l}\text { Lentilha com } \\
\text { Cenoura }\end{array}$ & 62,00 & 64,77 & 4,08 & 12,10 & 0,31 & 3,43 & 373,11 & 1,85 & 14,78 & 1,16 & 18,34 & 0,61 \\
\hline $\begin{array}{l}\text { Torta Vegana } \\
\text { de Ervilha }\end{array}$ & 43,26 & 70,09 & 3,88 & 8,86 & 3,05 & 0,70 & 123,30 & 1,76 & 28,74 & 0,07 & 3,55 & 0,41 \\
\hline Média $\pm D P$ & $38,14 \pm 12,12$ & $66,96 \pm 2,34$ & $\begin{array}{c}4,06 \pm \\
0,44\end{array}$ & $\begin{array}{l}11,26 \\
\pm 1,06\end{array}$ & $\begin{array}{c}1,14 \pm \\
0,83\end{array}$ & $\begin{array}{c}2,46 \pm \\
1,09\end{array}$ & $\begin{array}{r}70,64 \\
\pm 128,43\end{array}$ & $\begin{array}{c}1,48 \pm \\
0,47\end{array}$ & $\begin{array}{c}26,22 \pm \\
11,36\end{array}$ & $\begin{array}{c}0,48 \pm \\
0,34\end{array}$ & $\begin{array}{c}18,88 \pm \\
11,70\end{array}$ & $\begin{array}{l}1,00 \pm \\
0,45\end{array}$ \\
\hline $\begin{array}{l}\text { Coeficiente de } \\
\text { Variação (\%) }\end{array}$ & 31,78 & 3,49 & 10,76 & 9,38 & 72,58 & 44,48 & 181,81 & 31,93 & 43,33 & 70,91 & 61,94 & 45,18 \\
\hline
\end{tabular}

Legenda: PTN: Proteína; CHO: Carboidratos. LIP: Lipídeos; Vit. A: Vitamina A; Vit. C: Vitamina C; Ca: Cálcio; Zn: Zinco; Mg: Magnésio; Fe: Ferro.

Fonte: Autores.

Quando comparadas às recomendações nutricionais por refeição do PNAE, verificou-se variação no conteúdo de macronutrientes com percentuais respectivos de 38,33 a 53,81 para proteínas, 20,18 a 27,74 nos carboidratos e 4,56 a 44,85 de lipídios. Em relação aos micronutrientes e fibras, o percentual de contribuição na recomendação das preparações foi de: vitamina A (8,55 a 466,39), vitamina C (16,00 a 37,60), magnésio (13,19 a 131,81), ferro (20,50 a 95,00), zinco (7,00 a 116,00), cálcio $(8,14$ a 29,82) e fibras $(14,00$ a 73,40) (Tabela 2).

A variação do custo por porção dessas preparações foi de $R$ \$ 0,18 (torta vegana de ervilha) a $R$ \$ 0,46 (almôndegas de feijão branco), com média de $\mathrm{R} \$ 0,29 \pm 0,09$.

$\mathrm{Na}$ tabela 3 estão dispostas as informações nutricionais por porção das preparações à base de soja. Verificou-se que o peso médio da porção foi de $38,19 \pm 20,88 \mathrm{~g}$ e do valor energético igual a 63,52 $\pm 6,61 \mathrm{kcal}$ (Tabela 3). Ademais, os 
macronutrientes contribuíram em média com 21,23\% para proteínas, 43,36\% para carboidratos e 39,46\% nos lipídios, em relação ao fornecimento de energia nas preparações desse grupo.

Os maiores valores de fibras (2,51 g), vitamina A (203,17 g), zinco (0,64 mg) e magnésio (35,53 mg) encontram-se no hambúrguer de soja. Para vitamina $\mathrm{C}$ e ferro, os maiores valores foram atribuídos a mini almôndega de PTS. Além disso, a preparação que apresentou maior nível de proteínas foi o estrogonofe de PTS (Tabela 3).

Tabela 3. Composição nutricional por porção das preparações vegetarianas à base de soja propostas para o público infantil. Vitória - ES, 2019/2020.

\begin{tabular}{|c|c|c|c|c|c|c|c|c|c|c|c|c|}
\hline Preparação & $\begin{array}{l}\text { Porção } \\
\text { (g) }\end{array}$ & $\begin{array}{c}\text { Valor } \\
\text { energético } \\
\text { (kcal) }\end{array}$ & $\begin{array}{l}\text { PTN } \\
(\mathrm{g})\end{array}$ & $\begin{array}{c}\text { CHO } \\
(\mathrm{g})\end{array}$ & $\underset{(g)}{\text { LIP }}$ & $\begin{array}{l}\text { Fibras } \\
\text { (g) }\end{array}$ & $\begin{array}{l}\text { Vit.A } \\
(\text { mcg) }\end{array}$ & $\begin{array}{l}\text { Vit.C } \\
\text { (mg) }\end{array}$ & $\begin{array}{c}\mathrm{Ca} \\
(\mathbf{m g})\end{array}$ & $\begin{array}{c}\mathrm{Zn} \\
(\mathbf{m g})\end{array}$ & $\begin{array}{c}\mathrm{Mg} \\
(\mathbf{m g})\end{array}$ & $\begin{array}{c}\mathrm{Fe} \\
(\mathrm{mg})\end{array}$ \\
\hline $\begin{array}{lr}\text { Charuto } & \text { de } \\
\text { Repolho } & \text { com } \\
\text { PTS e } & \text { Arroz } \\
\text { Integral } & \end{array}$ & 45,52 & 51,82 & 2,04 & 7,52 & 1,69 & 1,37 & 13,86 & 6,58 & 12,93 & 0,18 & 11,47 & 0,22 \\
\hline $\begin{array}{l}\text { Estrogonofe de } \\
\text { PTS }\end{array}$ & 75,20 & 60,69 & 4,72 & 7,15 & 1,57 & 1,59 & 6,01 & 1,13 & 5,05 & 0,08 & 3,96 & 0,14 \\
\hline Farofa de PTS & 15,00 & 71,04 & 1,55 & 6,03 & 4,65 & 0,88 & 0,84 & 0,48 & 4,82 & 0,05 & 3,09 & 0,04 \\
\hline Média $\pm D P$ & $\begin{array}{c}38,19 \pm \\
20,88\end{array}$ & $63,52 \pm 6,61$ & $\begin{array}{c}3,37 \pm \\
1,32\end{array}$ & $\begin{array}{c}6,88 \pm \\
0,90\end{array}$ & $\begin{array}{c}2,79 \pm \\
1,13\end{array}$ & $\begin{array}{c}1,61 \pm \\
0,54\end{array}$ & $\begin{array}{c}46,68 \pm \\
78,74\end{array}$ & $\begin{array}{c}3,47 \pm \\
3,34\end{array}$ & $\begin{array}{c}9,01 \pm \\
3,53\end{array}$ & $\begin{array}{c}0,29 \pm \\
0,25\end{array}$ & $\begin{array}{c}15,26 \pm \\
13,15\end{array}$ & $\begin{array}{c}1,16 \pm \\
1,25\end{array}$ \\
\hline $\begin{array}{ll}\text { Coeficiente } & \text { de } \\
\text { Variação }(\%) & \end{array}$ & 54,69 & 10,41 & 39,15 & 13,07 & 40,62 & 33,90 & 180,26 & 96,32 & 39,14 & 85,93 & 86,18 & 108,06 \\
\hline
\end{tabular}

Legenda: PTN: Proteína; CHO: Carboidratos. LIP: Lipídeos; Vit. A: Vitamina A; Vit. C: Vitamina C; Ca: Cálcio; Zn: Zinco; Mg: Magnésio; Fe: Ferro.

Fonte: Autores.

Ao comparar as preparações à base de soja com as recomendações do PNAE verificou-se que os percentuais respectivos do conteúdo de macronutrientes de: proteínas (18,51 a 56,19), carboidratos $(13,58$ a 18,72) e lipídios $(23,09$ a 68,39). Para micronutrientes e fibras os percentuais respectivos de contribuição na recomendação oscilou para: vitamina A (1,05 a 253,96), vitamina C (9,53 a 173,80), magnésio (11,91 a 136,65), ferro $(2,01$ a 157,50), zinco (4,52 a 64,00), cálcio $(3,01$ a 8,08$)$ e fibras $(17,56$ a 50,20$)$

O custo por porção variou de R\$ 0,18 (farofa de PTS) a R \$ 0,64 (estrogonofe de PTS) com média de R\$ 0,40 $\pm 0,18$.

As composições nutricionais dos pratos de origem animal oferecidos no CEI avaliado estão dispostas na Tabela 4. Comparando-as com as das preparações vegetarianas desenvolvidas (Tabelas 1 a 3), verifica-se que estas últimas apresentaram valor calórico, de macronutrientes e micronutrientes superiores. 
Tabela 4. Composição nutricional por porção dos pratos principais de origem animal ofertados em um CEI. Vitória - ES, $2019 / 2020$.

\begin{tabular}{|c|c|c|c|c|c|c|c|c|c|c|c|c|}
\hline Preparação & $\begin{array}{l}\text { Porção } \\
\text { (g) }\end{array}$ & $\begin{array}{c}\text { Valor } \\
\text { energético } \\
\text { (kcal) }\end{array}$ & $\begin{array}{c}\text { PTN } \\
(\mathrm{g})\end{array}$ & $\underset{(\mathrm{g})}{\text { CHO }}$ & $\underset{(g)}{\text { LIP }}$ & $\begin{array}{l}\text { Fibras } \\
\quad(g)\end{array}$ & $\begin{array}{l}\text { Vit.A } \\
\text { (mcg) }\end{array}$ & $\begin{array}{l}\text { Vit.C } \\
\text { (mg) }\end{array}$ & $\begin{array}{c}\mathrm{Ca} \\
(\mathrm{mg})\end{array}$ & $\begin{array}{l}\mathbf{Z n} \\
(\mathbf{m g})\end{array}$ & $\begin{array}{l}\mathrm{Mg} \\
(\mathrm{mg})\end{array}$ & $\begin{array}{c}\mathbf{F e} \\
(\mathrm{mg})\end{array}$ \\
\hline Frango Desfiado & 11,00 & 21,52 & 3,40 & 0,00 & 0,77 & 0,00 & 0,99 & 0,00 & 1,65 & 0,13 & 2,97 & 0,11 \\
\hline Ovo Cozido & 12,00 & 17,52 & 1,59 & 0,07 & 1,14 & 0,00 & 3,84 & 0,00 & 5,88 & 0,14 & 1,32 & 0,18 \\
\hline $\begin{array}{l}\text { Coeficiente de } \\
\text { Variação }(\%)\end{array}$ & 8,33 & 22,77 & 37,79 & 173,21 & 29,03 & 0,00 & 123,83 & 0,00 & 105,30 & 120,07 & 38,12 & 57,85 \\
\hline
\end{tabular}

Legenda: PTN: Proteína; CHO: Carboidratos. LIP: Lipídeos; Vit. A: Vitamina A; Vit. C: Vitamina C; Ca: Cálcio; Zn: Zinco; Mg: Magnésio; Fe: Ferro.

Fonte: Autores.

De acordo com a quantidade de nutrientes por refeição recomendada pelo PNAE, os percentuais respectivos de proteínas, lipídeos e energia das opções proteicas à base de alimentos de origem animal no CEI em questão corresponderam a: 41,31, 20,74 e 10,21 na carne moída; 40,48, 11,32 e 7,97 no frango desfiado; e a 18,93, 16,76 e 6,49 no ovo cozido. Quanto ao conteúdo de micronutrientes destas preparações identificou-se o percentual respectivo para: vitamina A $(0,00$, 1,24 e 4,80), magnésio (8,50, 11,42 e 5,08), ferro (17,50, 5,50 e 9,00), zinco (105,00, 13,00 e 14,00), cálcio (0,33, 1,03 e 3,68) (dados não demonstrados em tabela).

\section{Discussão}

No presente estudo foi possível testar e padronizar preparações vegetarianas que atendem às particularidades do público infantil, com potencial de inserção em cardápios escolares. Cabe ressaltar que as porções estimadas apresentaram valor energético, macronutrientes, micronutrientes e fibras diversificadas e satisfatórias, que contribuem positivamente para o fornecimento dos nutrientes preconizados pelo PNAE.

Diante disso, destaca-se que estimular e promover hábitos de alimentação saudável na infância de modo regular e diversificado proporciona benefícios à saúde que poderão perdurar durante toda a vida (O’Connor, 2011). Para isso, nota-se que o desenvolvimento e oferta de preparações à base de produtos de origem vegetal para crianças se mostra importante, como forma de incentivar diferentes exposições ao paladar, estimulando o aprendizado sensorial, para que dessa forma seja possível diversificar e melhorar a ingestão de nutrientes, vegetais e alimentos à base deles na primeira infância (DeCosta, Møller, Frøst \& Olsen, 2017; Nekitsing, Hetherington \& Blundell-Birtill, 2018).

Sabaté e Wien (2010), destacam também que a inserção de preparações vegetarianas ofertadas em redes de ensino, contribuem significativamente na ampliação de novos sabores, bem como, na introdução e opções variadas de alimentos fontes de proteína, que resultam no desenvolvimento de bons hábitos alimentares, além de ressaltar que o estilo de alimentação baseado em vegetais precisa ser estimulado como incentivo à saúde humana e do meio ambiente.

Neste sentido, Monteiro et al. (2019) realizaram um estudo em uma instituição escolar no interior de São Paulo que oferece alimentação ovolactovegetariana aos alunos, com objetivo de adequar qualitativamente o cardápio. Foram inseridos ingredientes nas preparações ofertadas visando agregar variedade e valor nutricional, tal como incluir novas preparações ovolactovegetarianas no cardápio, a fim de torná-lo mais atrativo. Os alimentos foram propostos levando em conta as 
necessidades nutricionais comuns na infância e as particularidades de uma dieta vegetariana. Na refeição principal, foi realizada uma intervenção proteica com inclusão de leguminosas como grão de bico, ervilha, lentilha, feijões e dos pseudocereais como quinoa e amaranto. Os autores observaram que antes da intervenção as únicas leguminosas ofertadas eram o feijão e a ervilha, de forma repetida e monótona ao longo da semana. No entanto, após a inclusão de outras leguminosas, foi possível manter boa oferta de aminoácidos e aumentar a variedade das preparações, melhorando o atendimento das necessidades proteicas.

Semelhante a pesquisa de Monteiro et al. (2019), o presente estudo se baseou em desenvolver preparações vegetarianas advindas de leguminosas. Ressalta-se o papel deste grupo de alimentos como uma alternativa viável para substituição da carne, em virtude do alto teor de fibra alimentar, carboidratos complexos, proteínas, vitaminas do complexo B e minerais, além do baixo conteúdo de gorduras saturadas (Brasil, 2014; Fraga, Alcântra, Weber \& Setaro, 2020). Dessa forma, diversas pesquisas com foco no desenvolvimento de produtos a partir das leguminosas para diferentes públicos tem sido conduzida.

Nagagata et al. (2020) desenvolveram três tipos de hambúrgueres veganos à base das leguminosas, compreendendo a soja, feijão vermelho e grão de bico com finalidade de avaliar a composição centesimal. O hambúrguer de grão de bico apresentou maior valor de lipídios com alto teor de ácidos graxos ômega 3, justificado pela presença de farinha de linhaça na preparação. Esta mesma preparação também apresentou quantidades significativas de fibras $(8,15 \mathrm{~g} \mathrm{em} 100 \mathrm{~g})$. O hambúrguer à base de soja destacou-se em teores proteicos, no entanto, todas as três receitas desenvolvidas foram consideradas fontes de proteínas, possibilitando inferir que opções vegetarianas desenvolvidas à base de leguminosas apresentam elevada qualidade nutricional. Vale ressaltar as semelhanças destes achados com os do presente estudo, onde as preparações à base de grão de bico e feijão que também apresentaram níveis nutricionais adequados em diversos nutrientes considerando a porção.

Entre as preparações desenvolvidas que englobaram feijão, ervilha e lentilha, nota-se que apresentaram bons valores nutricionais, capazes de satisfazer a recomendação. Diante disso, destaca-se os hambúrgueres de ervilha e lentilha, dado que estão entre as preparações que apresentaram os maiores valores de proteína por porção desenvolvidas no estudo, além de apresentarem valores satisfatórios de fibras alimentares, cálcio e ferro, evidenciando que combinações de ingredientes melhoram a composição nutricional do alimento. De tal modo, Mosca et al. (2014) desenvolveram e avaliaram uma receita de bolo de chocolate acrescido de feijão proposta para crianças de 3 a 12 anos, objetivando melhorar a qualidade nutricional da preparação, comparando tal preparação com a versão comum do bolo. Os autores observaram percentuais aumentados de ferro, proteínas e fibras entre os sólidos totais, o que representou um aumento de cerca de 16,2 \% de proteínas e $51 \%$ no teor de fibras. Perante o exposto, reconhece-se que preparações tendo como base as leguminosas melhoram o valor nutricional de preparações e das refeições para o público infantil, tanto nos cardápios de almoço e jantar quanto em lanches.

Outra pesquisa realizada por Lima, Garruti, Pinto, Magalhães e Machado (2017) objetivou desenvolver hambúrguer vegetal utilizando fibra de caju associada à proteína texturizada de soja submetida à dois tipos de tratamento para redução da fibra (prensagem mecânica associada ou não à maceração enzimática) e investigar o seu impacto nas características físicoquímicas, aceitação e estabilidade dos hambúrgueres. Os autores identificaram que as preparações apresentaram elevado teor de umidade e carboidratos e baixo teor de lipídeos. Em estudo anterior de Lima (2008), com desenvolvimento de hambúrgueres elaborados apenas com a fibra de caju foi encontrado benefícios com o acréscimo de proteína texturizada de soja, já que foi observado teor de umidade superior aos valores obtidos anteriormente, além de um aumento no aporte de proteínas (de $11 \%$ para aproximadamente $19 \%$ ) e redução no conteúdo de lipídios (de $16 \%$ a aproximadamente $3 \%$ ).

Farias et al. (2016) elaboraram quatro tipos de hambúrgueres funcionais à base de soja acrescidos de vegetais e frutas. Em relação a composição nutricional dos hambúrgueres os resultados de todas as amostras mantiveram-se próximos em relação ao teor de macronutrientes (carboidratos, proteínas e lipídeos). Além disso, quando comparados a uma opção de 
hambúrguer cárneo industrializado, as preparações do estudo apresentaram maior proporção de carboidratos e proteínas e, em média, 100 vezes menor teor de sódio, além de teores de fibras variando entre 3,18 a 4,13 g/unidade. Cumpre destacar que as formulações do estudo apresentaram características adequadas para o consumo. No âmbito desta investigação, resultados semelhantes foram verificados nas preparações à base de soja, onde as médias de nutrientes encontradas foram consideradas satisfatórias e também superiores às preparações de origem animal ofertadas em um CEI.

O presente estudo apresenta como pontos fortes a elaboração de preparações vegetarianas com teores nutricionais adequados para o público infantil capaz de compor refeições e serem incluídas em cardápios escolares, bem como, instigar práticas alimentares saudáveis e sustentáveis. Entretanto, vale ressaltar a ausência da análise sensorial das preparações desenvolvidas com o público-alvo como um fator limitante, uma vez que verificar a aceitação das opções pelo público em questão configura-se como uma importante ferramenta para determinar a viabilidade de inclusão de novas preparações na alimentação escolar.

Embora no presente estudo não tenha sido possível estimar o percentual do custo em relação ao recurso disponibilizado pelo FNDE, devido ao fato de se tratar de proposta de preparações isoladas e não de refeição, atualmente, o valor per capita repassado pela União aos estados e municípios para oferta da alimentação na pré-escola é de R \$ 0,53 (Brasil, 2020).

Ao comparar os valores de referência para a faixa de idade considerada, as preparações propostas apresentaram diferenças no aporte de nutrientes. Ressalta-se que apesar dos percentuais de contribuição à recomendação nutricional do PNAE variaram entre as preparações propostas neste estudo, tais recomendações são referentes às refeições como um todo e não às preparações isoladas. No entanto, reconhece-se que são as combinações e variedade das preparações do cardápio que resultarão na ingestão equilibrada de nutrientes necessários ao longo do dia (Lobato et al. 2016; Brasil, 2020).

\section{Conclusão}

As preparações vegetarianas desenvolvidas apresentaram composição nutricional satisfatória quanto aos macronutrientes, valor energético, fibras e micronutrientes, sendo ainda superiores às opções de origem animal avaliadas. Assim, denota-se que preparações à base de leguminosas sejam aptas a integrar o cardápio de escolares, salientando a necessidade da combinação entre as preparações que irão compor a refeição.

É indubitável que para a adequação da ingestão dietética deve-se considerar o padrão de dieta adotado pelos indivíduos, sobretudo combinando os alimentos entre si e variando o consumo diário, de forma a assegurar o aporte de nutrientes necessários à faixa etária em questão.

\section{Referências}

Azevedo, E. de. (2013). Vegetarianismo. DEMETRA: Alimentação, Nutrição \& Saúde, 8(0), 275-288.

Barbosa, L., Madi, L., Toledo, M. A., \& Rego, R. A. (2010). As tendências da alimentação. In Brasil Food Trends (pp. 39-47).

Brasil. (2005). Guia alimentar para Crianças menores de 2 anos. In Ministério da Saúde, Organização Pan-Americana da Saúde.

Brasil. (2014). Guia Alimentar para a População Brasileira. In Ministério da Saúde. Secretaria de Atenção Primária à Saude, Departamento de Atenção Básica.

Brasil. (2019). Alimentação Vegetariana no Programa Nacional de Alimentação Escola. Nota Técnica n 8 de 2019 , Ministério da Educação. Fundo Nacional de Desenvolvimento da Educação.

Brasil. (2019). Guia Alimentar para crianças brasileiras menores de 2 anos. In Ministério da Saúde. Secretaria de Atenção Primária à Saude, Departamento de Promoção da Saúde.

Brasil. (2020). Resolução Nº 06, de 08 de Maio de 2020, Fundo Nacional De Desenvolvimento Da Educação (FNDE). Diário Oficial da União (D.O.U).

Cabral, T. da S., Oliveira, V. V. de S., Barros, M. C. dos S., Raimundo, A. C. de L., Mariano, D. M. dos S., Bezerra, R. da S., Oliveira, K. C. P. do N., \& 
Vieira, A. C. S. (2020). Estimulação precoce na primeira infância: incentivando a cultura de paz em pré-escolares. Brazilian Journal of Health Review, 3(6), 19924-19932.

Couceiro, P., Slywitch, E., \& Lenz, F. (2008). Padrão alimentar da dieta vegetariana. Einstein (São Paulo), 6(3), $365-373$.

De Cosmi, V., Scaglioni, S., \& Agostoni, C. (2017). Early taste experiences and later food choices. Nutrients, 9(2), 1-9.

DeCosta, P., Møller, P., Frøst, M. B., \& Olsen, A. (2017). Changing children's eating behaviour - A review of experimental research. Appetite, 113, $327-357$.

Farias, P. K. S., Souza, S. D. O., Santana, I. M. de O., Prates, R. P., Gusmão, A. C. M., \& Soares, P. D. de F. (2016). Desenvolvimento e análise sensorial de diferentes tipos de hambúrgueres funcionais utilizando o reaproveitamento de alimentos. Caderno de Ciências Agrárias, 8(3), 7-14.

Fraga, K. S., Alcântara, P. H. G., Weber, M. L., \& Setaro, L. (2020). Adequação do Consumo Alimentar de Adeptos da Dieta Vegetariana Estrita. Lifestyle, 4(2), 73-86.

Instituto Brasileiro de Opinião Pública e Estatística. (2018). Pesquisa de Opinião Pública Sobre Vegetarianismo. IBOPE Inteligência, 1-24.

Leitzmann, C. (2014). Vegetarian nutrition: past, present, future. The American Journal of Clinical Nutrition, 100(suppl_1), 496S-502S.

Lima, J. R. (2008). Physical chemical and sensory characterization of vegetal hamburger elaborated from cashew apple. Ciencia e Agrotecnologia, 32(1), 191195.

Lima, J. R., Garruti, D. D. S., Pinto, G. A. S., Magalhães, H. C. R., \& Machado, T. F. (2017). Vegetal burgers of cashew fiber and texturized soy protein. Revista Brasileira de Fruticultura, 39(3), 7.

Lobato, L., Silva, S. G. da, Cramês, M., Santos, C. T., \& Graça, P. (2016). Planeamento de refeições vegetarianas para crianças em restauração coletiva: Princípios Base. Programa Nacional Para a Promoção Da Alimentação Saudável., 1-46.

Melina, V., Craig, W., \& Levin, S. (2016). Position of the Academy of Nutrition and Dietetics: Vegetarian Diets. Journal of the Academy of Nutrition and Dietetics, 116(12), 1970-1980.

Monteiro, B. D. A., De Paula, T. M., Da Silva, Z. V., Moretti, S., \& Pansani Maniglia, F. (2019). Best food combinations in meals offered at school lacto-ovovegetarian. Nutricion Clinica y Dietetica Hospitalaria, 39(1), 56-63.

Mosca, P. C., Oliveira, F. M., Zanardo, F. de C., Rosatto, F. M., Almeida, J. M., Pereira, E. M. S., \& Tavano, O. L. (2014). Composição E Aceitabilidade Entre Crianças De Uma Creche/Escola De Uberaba-MG De Bolo De Chocolate Adicionado De Grãos De Feijão Cozidos. Revista Brasileira de Produtos Agroindustriais, 16(4), 403-410.

Nagagata, B. A., Carvalho, C. F. de, Santos, L. P., Santana, I., Freitas, S. M. de L., \& Guimarães, R. R. (2020). Desenvolvimento de burgueres veganos: estudo com consumidores e pesquisa de mercado. Research, Society and Development, 9(7), 19.

Nekitsing, C., Hetherington, M. M., \& Blundell-Birtill, P. (2018). Developing Healthy Food Preferences in Preschool Children Through Taste Exposure, Sensory Learning, and Nutrition Education. Current Obesity Reports, 7(1), 60-67.

O’Connor, Á. (2011). Promoting healthy eating and an active lifestyle in schoolchildren. Nursing Standard, 25, 48-57.

Philippi, S. T. (2002). Tabela de Composição de Alimentos: suporte para decisão nutricional. Editora Gráfica Coronário, 2 , 135.

Sabaté, J., \& Wien, M. (2010). Vegetarian diets and childhood obesity prevention. American Journal of Clinical Nutrition, 91(5), $1525-1529$.

Teixeira, R. D. C. M. D. A., Molina, M. D. C. B., Flor, D. S., Zandonade, E., \& Mill, J. G. (2006). Estado nutricional e estilo de vida em vegetarianos e onívoros - Grande Vitória - ES. Revista Brasileira de Epidemiologia, 9(1), 131-143.

UNICAMP, U. E. de C. (2011). Tabela Brasileira de Composição de Alimentos - TACO. NEPA - Núcleio de Estudos e Pesquisas Em Alimentação., 4 , 161. 